\title{
Antarctic topography and kilometre-scale roughness de- rived from ERS-1 altimetry
}

\author{
LAURENCE Brisset AND FrédÉRIQUe RÉmy \\ UMR 39/GRGS (CNRS-CNES) 18 av. Edouard Belin, 31055 Toulouse Cedex, France
}

\begin{abstract}
The ERS-1 satellite has delivered altimetric data since 1992, enabling us to map most of the Antarctic ice-sheet topography south to $82^{\circ} \mathrm{S}$ with better precision than all previous techniques. An algorithm has been developed such that the accuracy of the height data reaches the sub-metre level. As a first step, an inverse method has been designed to map the large-scale global topography, which is of interest to the study of the ice-sheet flow dynamics. As a second step, an adapted inverse algorithm displays precisely the short-scale undulations which are controlled by the bedrock below the ice. Finally, variations in the back-scattered altimetric signal allow us to map directly the kilometre-scale roughness that is related to the basal-flow conditions. Together, these maps constitute an important data base for modelling the ice sheet.
\end{abstract}

\section{INTRODUCTION}

The ice-sheet topography plays an important role in icesheet-flow studies. On the one hand, large-scale topography controls flow directions and its accurate mapping may allow us to derive balance velocity of ice sheets. On the other hand, the knowledge of the topographic slope and of the ice thickness allows an estimate of the basal shear stress which is related to the deformational velocity of the ice.

The best way to obtain a global and precise topography of ice sheets is by satellite altimetry. Its coverage and precision allow us to improve our knowledge of ice-sheet flow; for example, a few attempts have been made to estimate rheological parameters, the Glen flow-law exponent $n$ and the activation energy $Q$ (Young and others, 1989; Rémy and Minster, 1993). The latter demonstrates the role of the topography in such studies. Using a precise altimetric topography deduced from Seasat, they found $n=1$ and $Q=70 \mathrm{~kJ} \mathrm{~mol}^{-1}$ for temperatures lower than $-10^{\circ} \mathrm{C}$, but using earlier maps (Drewry, 1983) they found $n=1.8$ and $Q=30 \mathrm{~kJ} \mathrm{~mol}^{-1}$ for the same conditions. For a typical value of stress of 0.5 bar, this leads to a difference of $40 \%$ between estimates of deformation velocity. Moreover, satellite altimetry provides time series that could yield estimates for long-term or seasonal variations in ice-sheet elevation. Zwally and others (1989) measured a mean increase in the southern Greenland ice sheet of $23 \mathrm{~cm}$ year $^{-1}$, using Geosat and Seasat altimeter data, while Andersen (1994) extracted an annual signal of mean amplitude of $40 \mathrm{~cm}$ over Greenland from the analysis of ERS-1 preliminary data.

Satellite altimetry also allows us to map shortwavelength features on ice sheets such as undulations $(\lambda=20 \mathrm{~km})$. The presence of these short-wavelength features has been attributed to the process of ice flowing over an irregular bedrock (Budd, 1970; Hutter and others, 1981) and it appears that in places they are a direct reflection of the basal topography. Their occurrence is also linked with basal conditions: whereas these features are enhanced in areas of high friction, the presence of subglacial lakes suppresses them (Ridley and others, 1993). Amplitude and wavelength of such features can be directly estimated by using satellite altimetry.

Nevertheless, altimetric mapping for ice-sheet dynamics presents some difficulties. First, it is important to correct the data for instrumental, orbit and surface slopeinduced errors. Among other things, we will see in the next section that, with insufficient care in the altimetric treatment, errors can induce a global underestimation of the surface slope. Secondly, the distribution of altimetric data is not homogeneous $(350 \mathrm{~m}$ separation along track, several kilometres between tracks), leading to distortions in the map of undulations. To prevent this, we must extrapolate carefully height measurements in the acrosstrack directions: the inverse method, that will be described later, partially corrects this effect. Finally, the height measurement is derived from a beam with a footprint of several kilometres and is thus distorted by the same scale topographic features (Wingham, 1995). A direct analysis of the radar-altimeter wave-form echoes will provide an independent estimation.

\section{ALTIMETRIC PROGESSING}

We used the ERS-1 35 d repeat cycle waveform altimeter product (WAP), delivered by the UK-Processing and Archiving Facility (UK-PAF). 


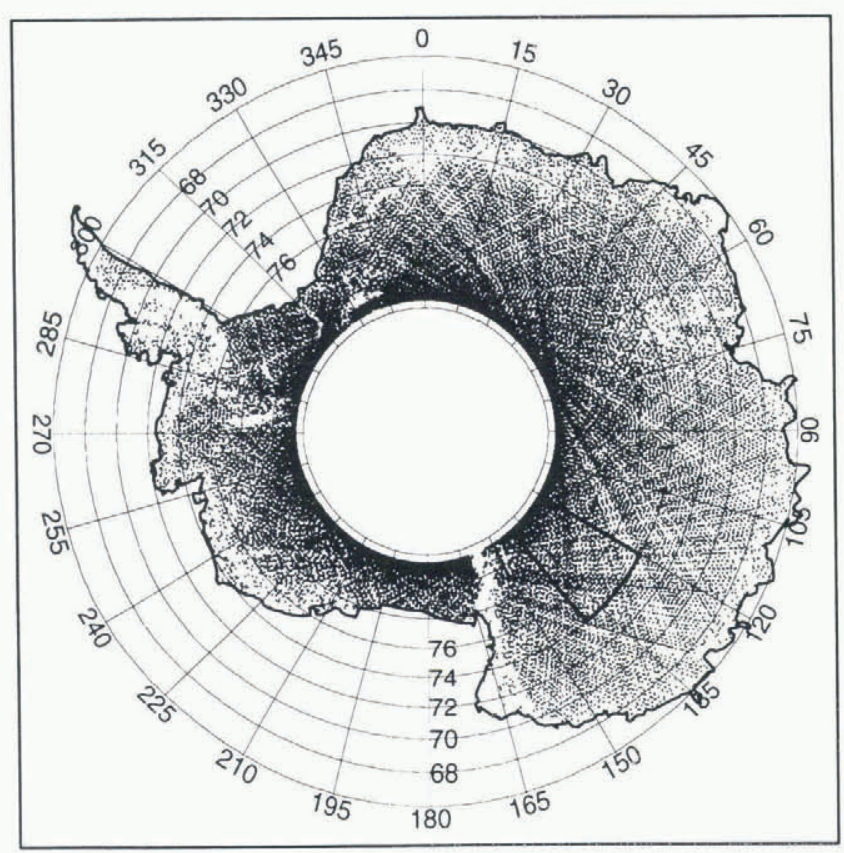

Fig. 1. Global coverage of the ERS-1 ice-mode altimeter data (cycle 88). Each dot represents 100 measurements of height. The average density varies from $0.2 \mathrm{data} \mathrm{km}^{-2}$ at $68^{\circ} \mathrm{S}$ to 6 dala $\mathrm{km}^{2}$ at $81.5^{\circ} \mathrm{S}$. The worst-covered zones are located near the coast, where there are rock outcrops.

Among other instruments, the ERS-1 payload comprises an altimeter working with two operational modes, designed to operate well over both the ocean and the continental ice. It covers all latitudes up to $\pm 81.4^{\circ}$, whereas Geosat and Seasat, its predecessors, were limited to $\pm 72.1^{\circ}$. ERS-1 therefore allows a global and synoptic control of most of Greenland and $80 \%$ of Antarctica.

In this paper, we have processed all data collected during the 88th $35 \mathrm{~d}$ repeat cycle, an ice-mode cycle in October 1992, and the whole 89th repeat cycle which was an ocean-mode cycle in November 1992. The ice-mode tracking is devoted to the tracking of steep topography and allows complete coverage of Antarctica; while oceanmode tracking, having a 4 times higher band width, is more accurate but loses track close to the margins. The mixing of both data sets provides a good compromise: ice mode for large-scale and global analysis and ocean mode for precise and short-scale analysis. In order to ensure maximum coverage, by minimizing seasonal effects, some missing tracks of the 89th cycle were replaced by the same tracks from neighbouring ocean cycles (83rd, 85th and 87 th). The instrument delivers 20 wave forms per second, or every $350 \mathrm{~m}$ along track, each wave form being the time series of samples of integrated echo power received by the altimeter. This provides about $3 \times 10^{6}$ height measurements on each complete cycle (Fig. 1). These raw data must be processed and corrected for many instrumental and physical effects. Only geophysical effects will be discussed here.

\section{Dry tropospheric error}

The interaction of the travelling wave with the dry troposphere creates a propagation delay. The resulting error is corrected using a theoretical formula derived from Saastromoinen (1972):

$$
\operatorname{cor}_{\text {tropo }}=2.2 \times 10^{-0.00006 h}
$$

where $h$ is the local ice-sheet altitude. This correction, $c o r_{\text {tropo }}$, is added to the altitude estimate.

\section{Retracking}

This correction takes into account uncertainties due to the characteristics of the onboard tracker. First, the onboard tracker is optimized for oceanic surfaces and is not able to keep the wave form returned by an undulating surface in the middle of its receiving window. Secondly, one can correct the height estimation for the penetration of the radar wave into the snow-pack. We must, however, not ignore the fact that an altimetric height represents an averaged measurement over a radar footprint of kilometre-scale radius.

The retracking used here is called erf retracking and consists of fitting an error-function solution to the radarreflected wave form sampled on 64 gates, using a least squares method (personal communication from F. Rémy and others, 1996). By this method, we determine the middle of the leading edge of the returned pulse, compared to the middle of the receiving window that represents the measurement given by the tracker, and offsets the induced error. The total returned energy is then estimated as the integral of the returned and retracked pulse (it is then corrected for the tracking error).

\section{Orbit error}

This effect requires careful treatment for two reasons. It is the dominant error in the interior of the continent, where slopes are small and the resulting errors are negligible. Secondly, it gets a very long-wavelength signal and can appear in the topographic map (Mazzega, 1986).

The geolocation of the satellite was obtained from the German Processing and Archiving Facility (D-PAF) precise orbit. This product contains the satellite position at a 20 s rate, which has to be interpolated in a Cartesian geocentric reference frame. Within our test region (latitude below $68^{\circ} \mathrm{S}$, longitude between $80^{\circ}$ and $150^{\circ} \mathrm{E}$ ), the r.m.s. of cross-over differences between ascending and descending passes decreases from $1.5 \mathrm{~m}$ with raw geolocation to $80 \mathrm{~cm}$ with our re-interpolated orbit. This value is the result of non-reproducible errors, including orbit error, wet tropospheric error and instrumental noise, and it is independent of slope error, which is dependent on slope geometry. It is unwise to compare these $80 \mathrm{~cm}$ r.m.s. with the $6.8 \mathrm{~m}$ found by Bamber (1994), because the latter map was obtained using the fast delivery altimeter data, with a $7 \mathrm{~km}$ along-track sampling and without retracking. The orbit error is generally a few decimetres but reaches metre level for several tracks and is well corrected within our inverse algorithm.

\section{Slope error}

This error is due to the shift of the reflecting point of the 
radar wave on the ice surface, in the upslope direction. Before proposing a correction for this error, let us briefly recall its characteristics, since it is the most critical for our study. First, it is dominant, except near the domes where the slopes are less than $1 \mathrm{~m} \mathrm{~km}^{-1}$. Secondly, it is difficult to correct with a single track, because we have no information on the slope in the across-track direction. Thirdly, this error not only depends on the surface slope of the reflecting surface but also on the curvature (Rémy and others, 1989): if $f(x)$ is the true topography along the upslope direction and $g(x)$ is the apparent one, "seen" by the satellite, then we can write, to second order,

$$
g(x)=f(x)+\frac{H}{2} \frac{f^{\prime}(x)}{1-H f^{\prime \prime}(x)}
$$

where $H$ is the satellite height, almost $800 \mathrm{~km}, f^{\prime}(x)$ and $f^{\prime \prime}(x)$, respectively, what we call surface slope and surface curvature, represent the first and second derivatives of the topography with distance in the upslope direction. $f^{\prime \prime \prime}(x)$ is supposed to be negligible.

The residual error is always positive and is about $40 \mathrm{~cm}$ for a slope of $1 \mathrm{~m} \mathrm{~km}^{-1}$ but it reaches $1.6 \mathrm{~m}$ for a slope of $2 \mathrm{~m} \mathrm{~km}^{-1}$, as found typically within the continent and $10 \mathrm{~m}$ for a slope of $5 \mathrm{~m} \mathrm{~km}$ '

Using Equation (1), we can see that the apparent slope $g^{\prime}(x)$ is, to second order,

$$
g^{\prime}(x)=\frac{f^{\prime}(x)}{1-H f^{\prime \prime}(x)} .
$$

If one does not take the curvature $f^{\prime \prime}(x)$ into account, the residual error on the slope $g^{\prime}(x)$ is about $0.1 f^{\prime}(x)$ for a typical curvature value of $10^{-7} \mathrm{~m}^{-1}$. Moreover, because of the near-parabolic shape of the Antarctic ice sheet, slope and curvature are geographically linked, a poor slope correction will cause a general underestimation of the derived slope, and thus an underestimation of the derived shear stress.

Our method consists of computing the exact surface by fitting the two-dimensional apparent topography with a biquadratic form. Slope and curvature parameters are then determined with nine neighbouring grid points. The derivation of Equation (2) leads to

$$
g^{\prime \prime}(x)=\frac{f^{\prime \prime}(x)}{1-H f^{\prime \prime}(x)}
$$

so that

$$
f^{\prime \prime}(x)=\frac{g^{\prime \prime}(x)}{1+H g^{\prime \prime}(x)} .
$$

Equations (1), (2) and (4) then lead to

$$
f(x)=g(x)-\frac{H}{2} \frac{g^{\prime}(x)}{1+H g^{\prime \prime}(x)} .
$$

This technique has the advantage of being easy to implement. One can note that when $f^{\prime \prime}(x)=1 / H$, Equation (1) is unbounded. Indeed, in such a case, the curvature is too important and the first return of the radar wave has not been reflected by the bottom of the undulation. The determination of topography is actually limited to this curvature value. Fortunately, in Antarctica, the curvature of the topography does not reach this critical value, except near the coast.

\section{MAPPING THE TOPOGRAPHY AND SURFACE SLOPE USING A TOTAL INVERSE METHOD}

At this stage of processing, the altimetric data have been interpolated with a precise orbit and corrected for instrumental, atmospheric and tracking errors. Any residual errors still remaining are within the $80 \mathrm{~cm}$ r.m.s. cross-over error. In order to reduce this remainder error, we compute the topography with a total inverse technique, developed for ocean mapping with altimetric data (Mazzega and Houry, 1989) and adapted for icesheet mapping (Rémy and others, 1989). Each term of the error budget is taken into account (except slope error which is corrected at last), by describing its statistics in terms of the covariance function and the decorrelation length. The height signal we are seeking is modelled with a Gaussian function, defined by its maximum value that we call variance, and by its decorrelation length. This technique has several advantages. First, the knowledge of the statistics of the various components of the error budget help us to separate the error from the topographic signal. Secondly, the a posteriori error can be simultaneously computed. Finally, the full benefit of the inversion technique lies in the possibility of separating large-scale features from short-scale undulations. The spectrum of the large-scale signal is very different from that of the remainder errors and topographic undulations

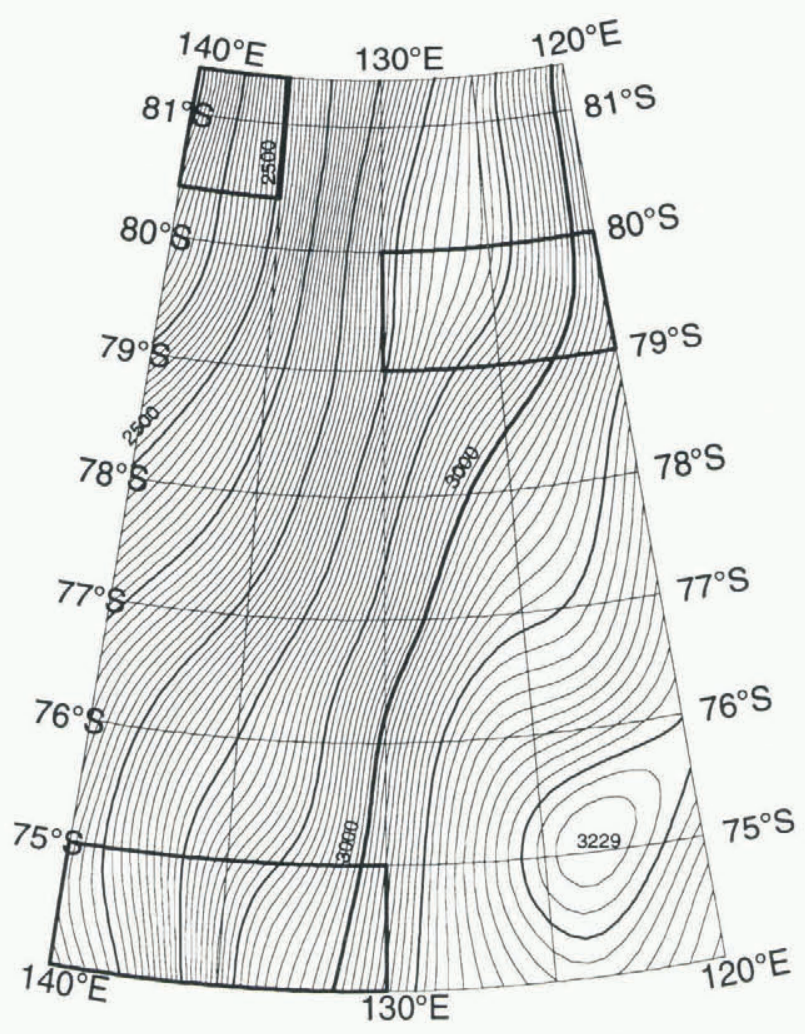

Fig. 2. Region of $500 \mathrm{~km} \times 800 \mathrm{~km}$, indicated in Figure 1, showing the large-scale topography, contoured at $10 \mathrm{~m}$ intervals. The $100 \mathrm{~km}$ wavelength signal is removed. 

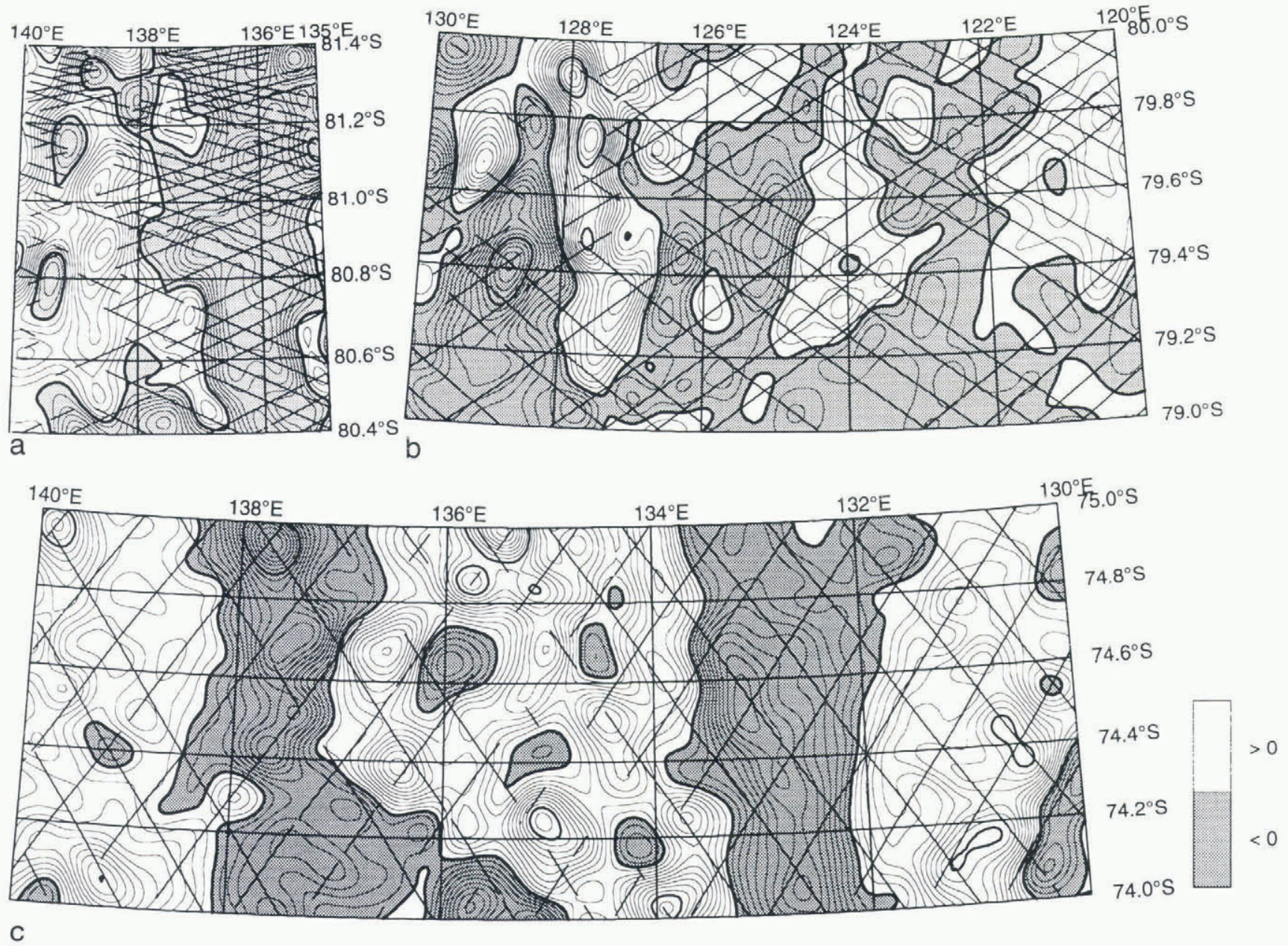

Fig. 3. Residuals obtained by the second-step inversion, superimposed on satellite tracks, for three small regions defined in Figure 2. We can see at $128^{\circ} \mathrm{E}(\mathrm{b})$ a strong kilometre-wavelength signal which is also detected on the back-scattered energy variations map (Fig. 8). Contour interval is $2 \mathrm{~m}$.

and we recover the topography in two steps: a large-scale inversion of the ice-mode cycle provides a mean surface covering most of Antarctica and a second iteration allows us to determine a very precise topography with the oceanmode cycle.

In the first step, variance of the signal has been set at $700 \mathrm{~m}$ and the decorrelation length is $150 \mathrm{~km}$. This distance is larger than the distance between tracks, so the inversion algorithm is not sensitive to the poor distribution of data. The resulting smooth topography is restored over a regular grid with steps of $0.5^{\circ}$ in longitude and $0.1^{\circ}$ in latitude (about $15 \times 10 \mathrm{~km}^{2}$ ). This map (Fig. 2 ) is used as a reference surface for the second step.

After subtracting the surface derived in the first step from the measured altitude of the ocean-cycle data, the resulting residuals were processed through the inversion algorithm. This residual signal, mostly a small-scale signal, shows the undulations typically of $10 \mathrm{~m}$ amplitude and $20 \mathrm{~km}$ wavelength. In the second-step inversion, the variance of the signal is set to $7 \mathrm{~m}$, when the variance of the orbit error is set to $1 \mathrm{~m}$ and the noise is set to $1 \mathrm{~m}$. The decorrelation length is very different for each component $20 \mathrm{~km}$ for signal, 1 cycle/revolution for orbit error, $350 \mathrm{~m}$ for noise) and both signal and errors are well separated. In fact, the space time structure of the various data errors is difficult to characterize, so that we prefer slightly to overestimate the a priori error variances. This choice will tend to slightly oversmooth the topographic signal. Figure 3 shows three small maps of residual topography from the area indicated on Figure 2. One can see on Figure 3a that coverage is dense, except at $140^{\circ} \mathrm{E}$, where strong undulations are visible. In such areas, the lack of data is due to failure of the onboard tracker over rough surfaces, and the same parts of the track are missing in other ocean cycles. At high latitudes, where the inter-track distance is less than the decorrelation length, the inversion algorithm is able to estimate the geolocation and value of a local extreme between two tracks (Fig. $3 \mathrm{a}$ and b). In that case, the a posteriori error, which is the difference between the $a$ priori error and the information gained through the inversion (Fig. 4a and b), is homogeneous and less than $1 \mathrm{~m}$ except where there are no data. In Figure 3c, undulations are found under the tracks; this is a consequence of the particular geographic sampling. Indeed, for latitudes lower than $75^{\circ} \mathrm{S}$, the distance between two tracks is too large to restore the small-scale features and so the algorithm fits topography on the reference only. This effect also explains the shape of the formal error shown in Figure 4c, where the error is maximum between two tracks. In fact, over such zones, undulations are not well recovered, as we do not have sufficient information on the across-track direction slope. 


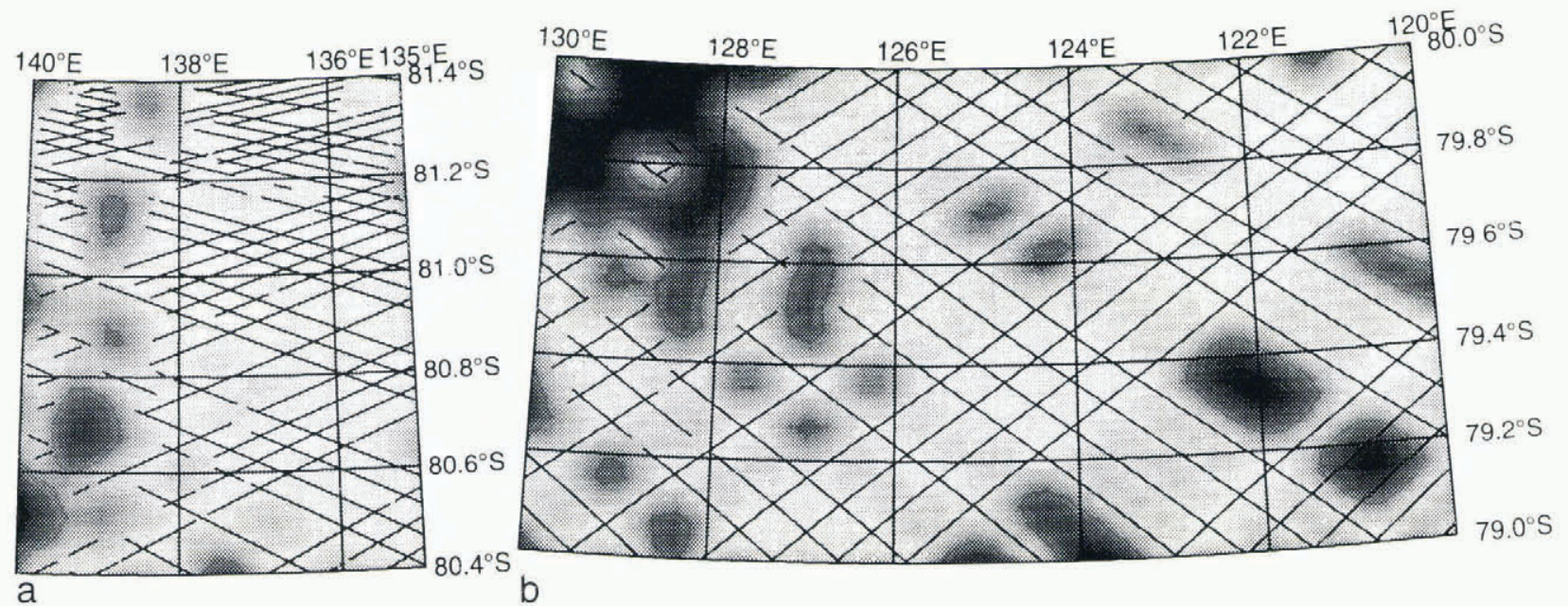

a b

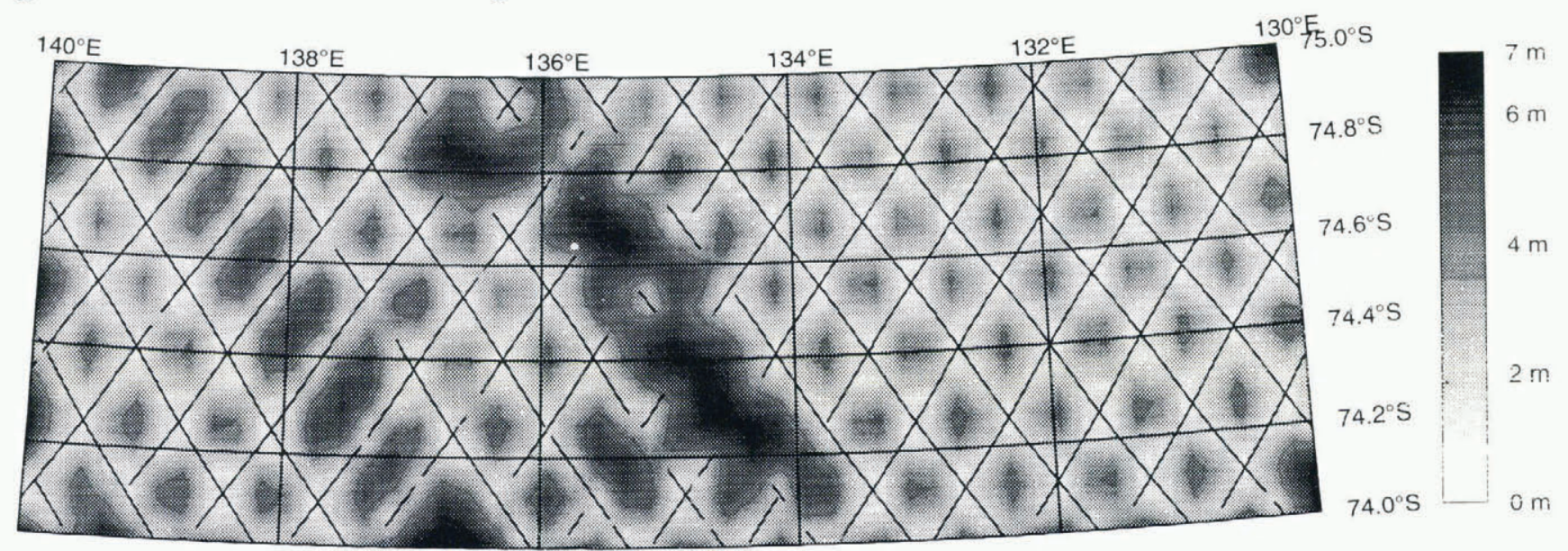

C

Fig. 4. The a posteriori error maps calculated within the inversion, for the areas defined in Figure 2. The satellite tracks are also drawn. Breaks in these tracks indicate that no data were collected. In (a) and (b), this error is almost homogeneous and sub-metric, whereas in (c) it is minimum only under tracks.

We will see in the next section that the estimation of the undulation characteristics from the along-track profiles induces a global underestimation of these features.

Finally, the second-step residuals are added to the large-scale topography in order to estimate the local surface slope and curvature and to compute the corresponding correction to be applied to the data (Equation (5)). Figure 5 shows this topography for our three regions. The same process yielded the final topography of the whole of Antarctica, which is presented on a grid of about $5 \mathrm{~km}$ (Fig. 6). We believe that the accuracy of this map is better than previous maps. There are certainly significant changes, for instance, Dome C, a precise description of which was needed for the ItalianFrench ice-core project Concordia, appears at $75.1^{\circ} \mathrm{S}$, $123.3^{\circ} \mathrm{W}, 60 \mathrm{~km}$ from its previous position. This has been confirmed by ground-based measurements. Other topographic features such as ice divides, domes and drainage basins are clearly identifiable.

Surface slopes derived from Figure 6 are shown in Figure 7. Slopes are less than $0.5 \mathrm{~m} \mathrm{~km}^{-1}$ nearer the dome or divide and increase in the downslope direction. Some anomalies are also apparent: for instance, flat regions such as Vostok lake $\left(76-78^{\circ} \mathrm{S}, 105^{\circ} \mathrm{E}\right)$, already mapped by Ridley and others (1993), Astrolabe Lake $\left(70^{\circ} \mathrm{S}, 135^{\circ} \mathrm{E}\right)$, or the great slope region along longitude $135^{\circ} \mathrm{E}$ which corresponds to an elongated bedrock feature (Drewry, 1983).

\section{MAPPING SMALL-SCALE FEATURES}

As explained in the introduction, small-scale features that correspond to kilometre-scale roughness directly reflect bedrock irregularities and basal conditions. Moreover, they are related to the small-scale shear-stress variations, that affect ice-sheet-flow modelling (Rémy and others, 1996b).

The mapping of these structures with satellitealtimeter data is critically dependent on the inter-track distance. As shown in Figure 3c, when the inter-track distance is large, the maximum values of the short-scale features are found under satellite tracks. This effect will be stronger at lower latitudes and as such undulations are strong. Moreover, the across-track widths of these structures depends strongly on the covariance length used in the mapping.

One can show that, if undulations are isotropically dome-shaped, as suggested by McIntyre and Drewry (1984) (i.e. if $h=A \exp \left(-2\left(\left(x^{2}+y^{2}\right) / \lambda^{2}\right)\right)$, where $\lambda$ is 

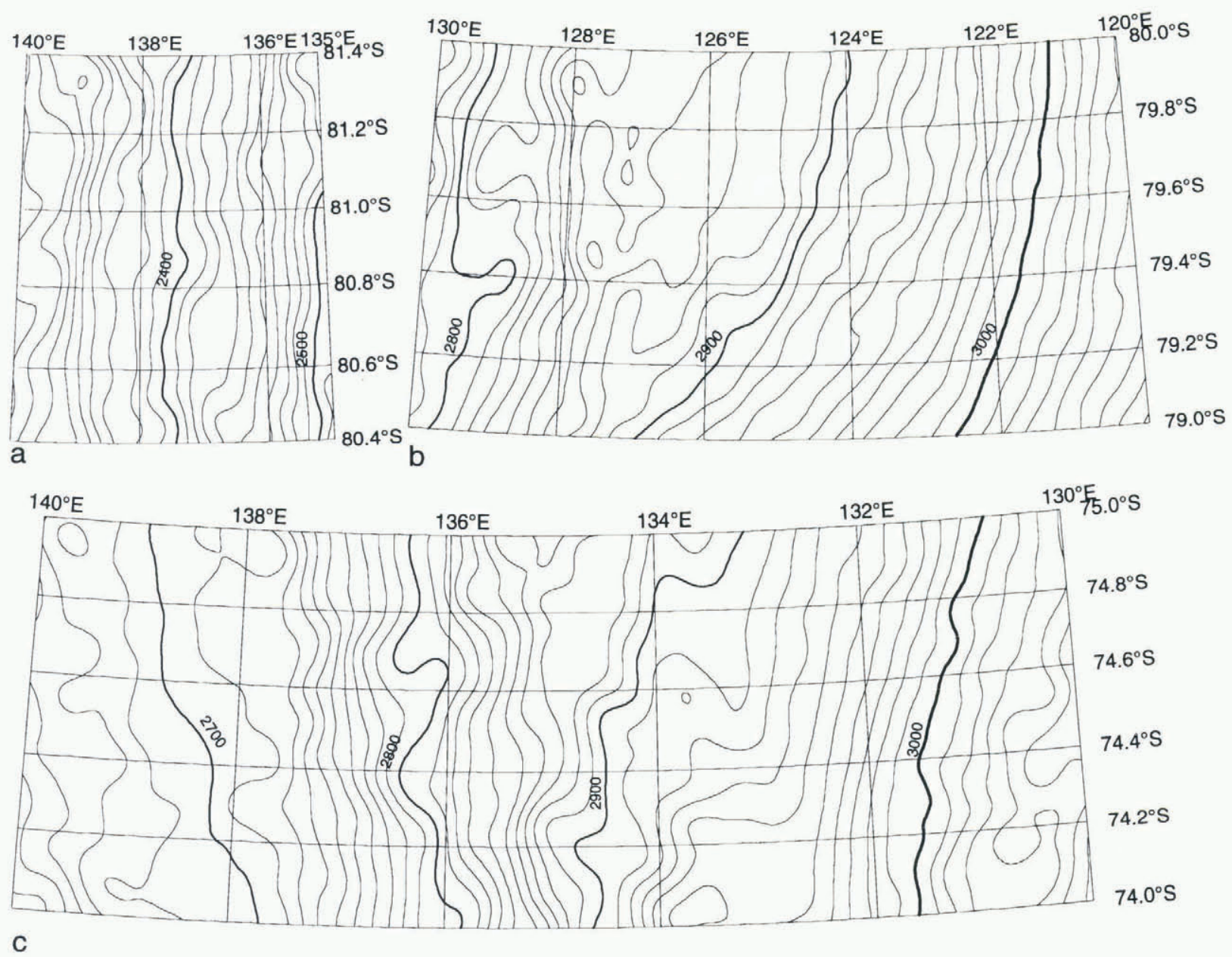

Fig. 5. The total topography in the three regions defined in Figure 2 by adding the second-step residuals to the large-scale topography. Contour interval is $10 \mathrm{~m}$.

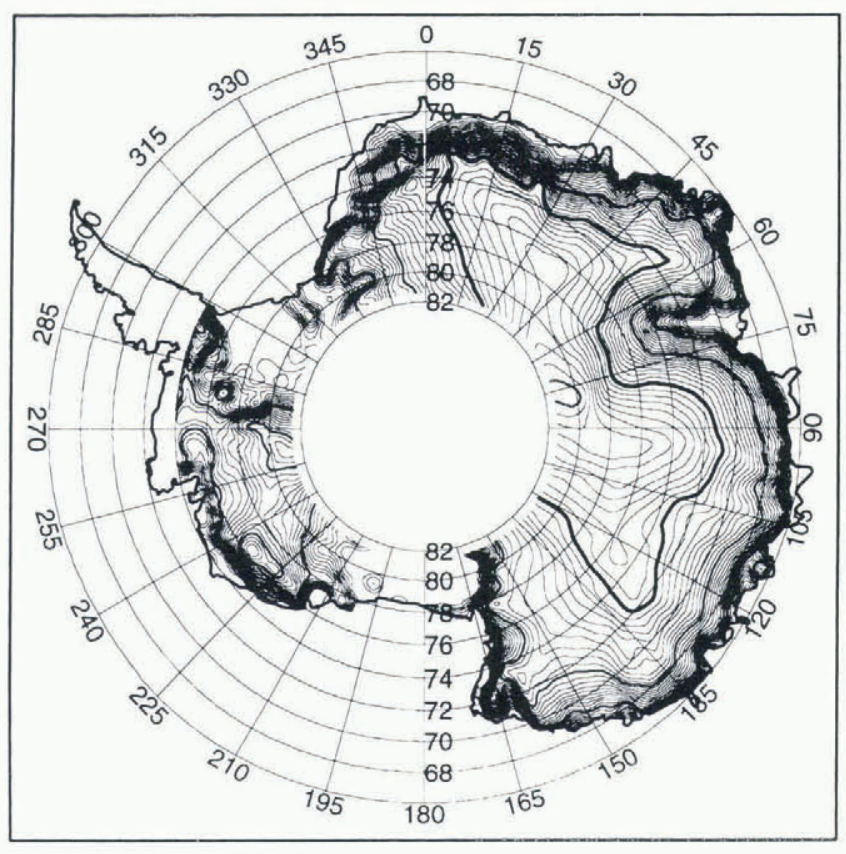

Fig. 6. Global topography of the Antartic ice sheet as determined over significant regions of the ERS-1 cycle 89 of the altimetric data set. Thin lines correspond to $100 \mathrm{~m}$ interval contour lines, medium-width lines to $1000 \mathrm{~m}$ interval contour lines and the thick one is $3000 \mathrm{~m}$. the wavelength, $A$ is the amplitude and $y$ is the acrosstrack distance), then the maximum amplitude as seen by the satellite will be $A \exp \left(-2\left(d^{2} / \lambda^{2}\right)\right)$, where $d$ is the nearest distance of the satellite track to the dome centre. If we do not consider the shift of the reflecting point due to the regional slope, $d$ is statistically uniformly distributed between 0 to $\lambda$, yielding to an average amplitude of $A \exp (-1 / 2)$ or about $60 \%$ of the real amplitude.

This fact suggests we should search for another way to estimate the amplitude of kilometre-scale undulations. Currently, we tend to ignore the back-scattered energy but the time series recorded by the altimeter can be thought of as a histogram of the received energy vs the arrival time and corresponds to a footprint of a few kilometres radius, depending on the local surface. This energy results from reflection both by surface microroughness, largely created by katabatic wind (Rémy and others, 1990) and by volume-scattering inside the snowpack (Ridley and Partington, 1988), while the short-scale spatial variations of this parameter are mostly due to the variations of the illuminated surface and to the kilometrescale curvature of the topography. Note that other mechanisms such as surface temperature and drifting snow also play a role but these meteorological phenomena only play a role on the $100 \mathrm{~km}$ spatial scale. Legresy and Rémy (paper in preparation) show that the amplitude of the variations of the energy $\delta \sigma$, calculated over a $50 \mathrm{~km}$ 


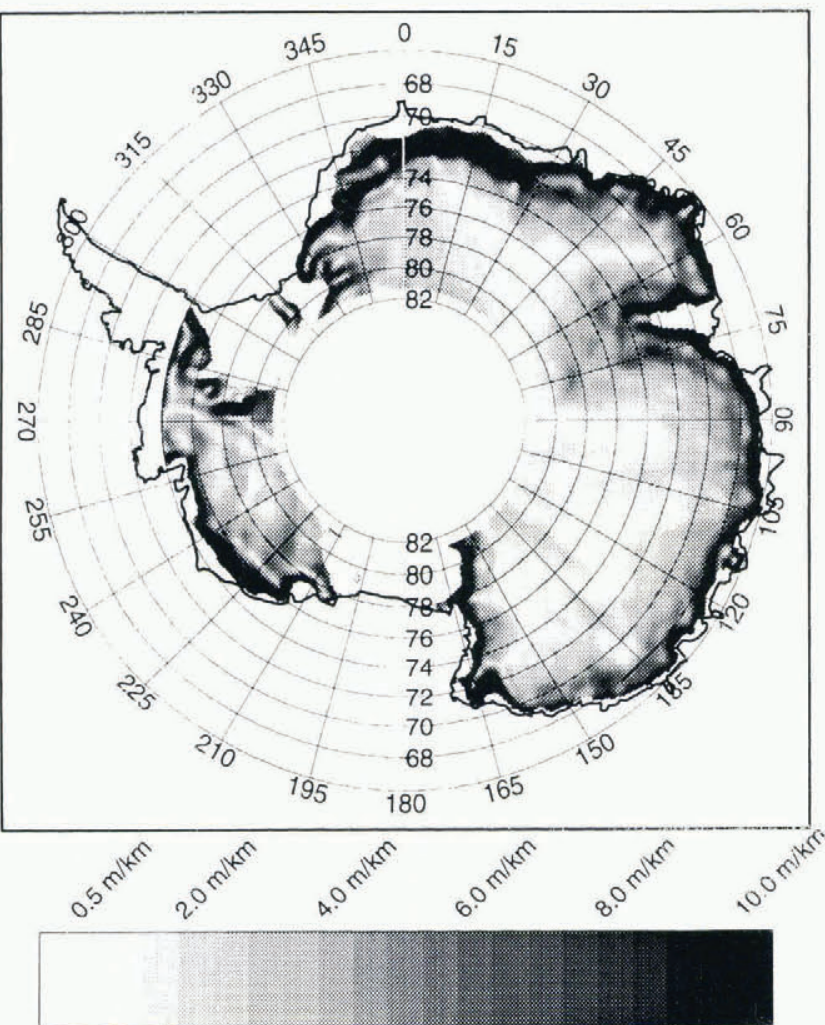

Fig. 7. Global surface slope derived from the topographic map. This map shows the pattern of the principal surface features.Fig. 7. Global surface slope derived from the topographic map. This map shows the pattern of the principal surface features.
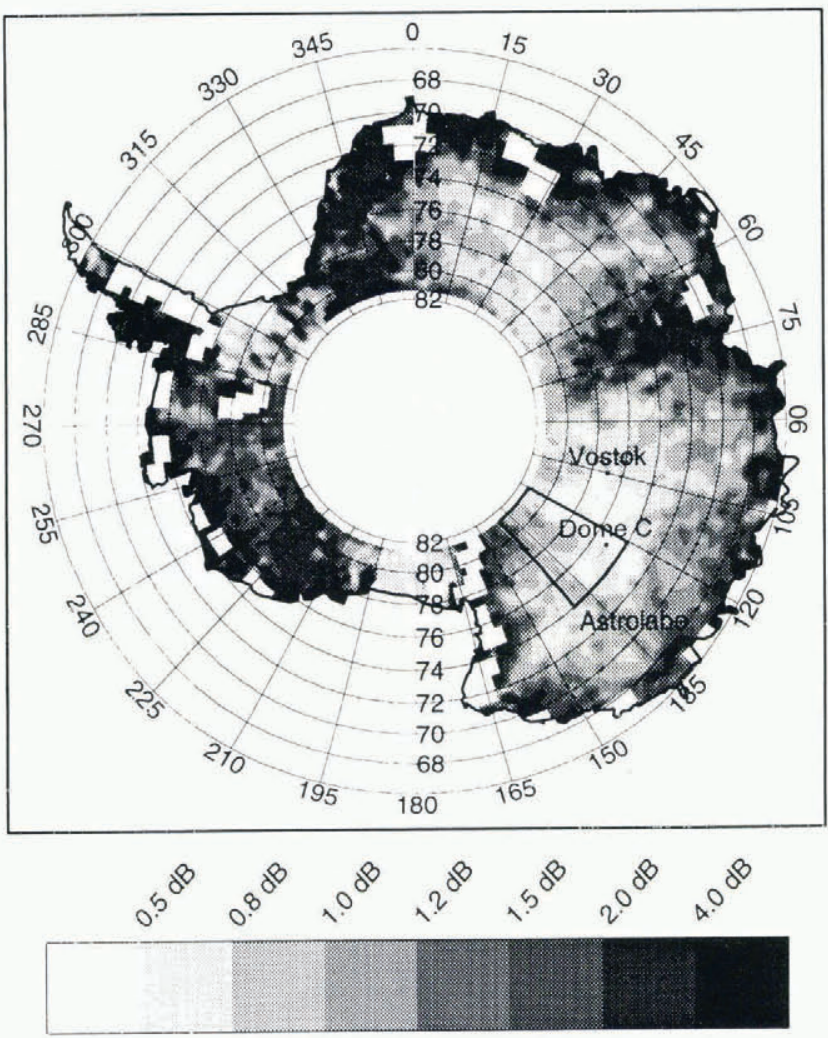

Fig. 8. Amplitude of the variation of the returned energ) (in $\mathrm{dB}$ ), averaged over $50 \times 50 \mathrm{~km}^{2}$ squares. This parameter is directly related to the undulation curvatures. scale, are related to undulations by

$$
\delta \sigma=10 \log (1-2 c H)
$$

where $c$ is the undulation curvature, $H$ is the satellite altitude and $\delta \sigma$ is expressed in $\mathrm{dB}$. $\delta \sigma$ yields the true characteristics of the undulations at the footprint scale. It is totally independent of the altimetric height, which is distorted near the coast or in the presence of strong undulations. This kilometre-scale curvature is directly linked to the small-scale variations of the slope and therefore is related to the accuracy of the restored surface slope.

The large-scale geographical distribution of this parameter, averaged over areas of $50 \times 50 \mathrm{~km}^{2}$ (Fig. 8), is strongly correlated with the surface slope (Fig. 7) (correlation of 0.7 for the set of 12000 grid points), as theoretically suggested by Hutter and others (1981). The region indicated in Figure 8, with a strong gradient, is the region mapped in Figure 2. This gradient is also visible in Figure $3 \mathrm{~b}$, where the lefthand side has far more undulations than the righthand part, and in Figure 3c, where a flat region is seen around $133^{\circ} \mathrm{E}$, corresponding to the minimum of $\delta \sigma$.

West Antarctica shows large values of $\delta \sigma$ (Fig. 8), as does East Antarctica near the coast, on the great convergence area, and where the bedrock is important (see $135^{\circ} \mathrm{E}$ ). A few low values can be observed, which correspond to the known subglacial lakes, as for example the Vostok lake $\left(76-78^{\circ} \mathrm{S}, 105^{\circ} \mathrm{E}\right.$; Ridley and others, 1993), the Dome C region or the Astrolabe Basin (Oswald and Robin, 1973).

\section{CONGLUSIONS}

Satellite altimetric observations above the ice sheet provide surface topographic and surface-slope maps, and contribute to glaciological understanding, by producing a small-scale curvature map which may be related to basal conditions. However, to be useful, these parameters must be carefully corrected for the principal altimetric errors. Error due to surface slope is critical, because it contains a systematic component not only related to surface slope but also to surface curvature, which generally correlate over the ice sheet. The use of the two-stage formulation presented here reduces the residual error and prevents systematic bias. The inverse technique used allows the restitution of the a posteriori error, which is around $1 \mathrm{~m}$ at high latitude but reaches several metres near $70^{\circ} \mathrm{S}$. Because the linear sampling of altimeter data does not allow the correct retrieval of the small-scale topography, we prefer to use the variations in backscattered energy which are directly linked with the topographic curvature at kilometre scale. We show that this parameter is strongly related to surface slope and to the presence of several subglacial lakes, and so constitutes a valuable complement to height measurements.

Finally, the most important problem preventing submetre precision altimetry and high-precision slope mapping of the whole continent is the inadequate coverage. The map is, however, better than the earlier ones. The $168 \mathrm{~d}$ repeat cycle will give better resolution than the $35 \mathrm{~d}$ repeat cycle and it promises to provide a coverage five 
times as dense as the $35 \mathrm{~d}$ repeat one, and so it will allow good estimation of kilometre-scale roughness and its spatial distribution at low latitudes.

\section{ACKNOWLEDGEMENTS}

J.M. Lemoine, from the Laboratoire de Dynamique Planétaire is greatly thanked for having helped us to compute the D-PAF orbit. Thanks are due to P. Mazzega and B. Legresy from the UMR39 (CNRS-CNES), and P. Vincent from CNES for their useful comments.

\section{REFERENGES}

Andersen, O.B. 1994. ERS-1 altimetry over the Greenland ice sheet: preliminary investigations of annual variations. Geophys. Res. Lell., $21(15), 1655-1658$

Bamber, J. L. 1994. A digital elevation model of the Antarctic ice sheet derived from ERS-1 altimeter data and comparison with terrestrial measurements. Ann. Glaciol., 20, 48-54

Budd, W. F. 1970. Ice flow over bedrock perturbations. J. Glaciol., 9 55), $29-48$.

Drewry, D.J. 1983. The surface of the Antarctic ice sheet. In Drewry, D.J., ed. Antarctica: glaciological and geophysical folio. Cambridge, Scott Polar Research Institute, Sheet 2.

Hutter, K., F. Legerer and U. Spring. 1981. First-order stresses and deformations in glaciers and ice sheets. 7. Glaciol., 27 (96), 227-270.

McIntyre, N.F. and D.J. Drewry. 1984. Modelling ice-sheet topography surfaces for the ERS-1's altimeter. ESA J., 8, $261-274$.

Mazzega, P. 1986. How radial orbit errors are mapped in altimetric surfaces. J. Geophys. Res., 91 C5), $6609-6628$.

Mazzega, P. and S. Houry, 1989. An experiment to invert Seasat altimetry for the Mediterranean and Black Sea mean surfaces. Geophys. J., 96, 259272.

Oswald, G.K.A. and G.de Q. Robin. 1973. Lakes beneath the Antarctic ice sheet. Vature, 245 5423), 251254.

Rémy, F. and J. F. Minster. 1993. Precise altimetric topography in icesheet flow studies, Ann. Glaciol., 17, 195-200.

Rémy, F., P. Mazzega, S. Houry, C. Brossier and J. F. Minster. 1989. Mapping of the topography of continental ice by inversion of satellite-altimeter data. J. Glaciol., 35119$)$, 98-107.

Rémy, F., C. Brossier and J.F. Minster. 1990. Intensity of satellite radar-altimeter return power over continental ice: a potential measurement of katabatic wind intensity. J. Glaciol., 36 123), 133-142.

Rémy, F., C. Ritz and L. Brisset. 1996. Ice-sheet flow features and rheological parameters derived from precise altimetric topography. Ann. Glaciol., 23, (see paper in this volume).

Ridley, J. K. and K. C. Partington. 1988. A model of satellite radar altimeter return from ice sheets. Int. J. Remole Sensing, 9 4), 601-624.

Ridley, J. K.. W. Cudlip and S. W. Laxon. 1993. Identification of subglacial lakes using ERS-1 radar altimeter. J. Glaciol., 39 133), $625-634$.

Saastromoinen, J. 1972. Atmospheric correction for the troposphere and stratosphere in radio ranging of satellites. In Henricksen, S. W., A. Mancini and B. H. Chovitz, eds. The use of artificial satellites for geodesy. Washington, DC, American Geophysical Union, Geophysical Monograph 15.

Wingham, D.J. 1995. A method for determining the average height of a large topographic ice sheet from observations of the echo received by a satellite altimeter. J. Glaciol., 41 137), $125-141$.

Young, N. W., I. D. Goodwin, N. W.J. Hazelton and R.J. Thwaites. 1989. Measured velocities and ice flow in Wilkes Land, Antarctica. Ann. Glaciol., 12, $192-197$.

Zwally, H.J., A. C. Brenner, J. A. Major, R. A. Bindschadler and J. G. Marsh. 1989. Growth of Greenland ice sheet: measurement. Science. $246(4937), 1587-1589$. 